\title{
Zinc Oxide Nanoparticles Alleviate Chilling Stress in Rice (Oryza Sativa L.) by Regulating Antioxidative System and Chilling Response Transcription Factors
}

\author{
Yue Song ${ }^{1,2}$, Meng Jiang ${ }^{2}\left(\mathbb{D}\right.$, Huali Zhang ${ }^{3}$ and Ruiqing $\mathrm{Li}^{1, *}$ \\ 1 College of Agronomy, Anhui Agricultural University, Hefei 230036, China; yuesong@zju.edu.cn \\ 2 National Key Laboratory of Rice Biology, Institute of Crop Sciences, Zhejiang University, \\ Hangzhou 310029, China; mengjiang@zju.edu.cn \\ 3 State Key Laboratory of Rice Biology, Chinese National Center for Rice Improvement, \\ China National Rice Research Institute, Hangzhou 310029, China; zhanghuali621@126.com \\ * Correspondence: liruiqing@ahau.edu.cn
}

\section{check for} updates

Citation: Song, Y.; Jiang, M.; Zhang, H.; Li, R. Zinc Oxide Nanoparticles Alleviate Chilling Stress in Rice (Oryza Sativa L.) by Regulating Antioxidative System and Chilling Response Transcription Factors. Molecules 2021, 26, 2196. https://doi.org/10.3390/ molecules26082196

Academic Editor: Alexandru Mihai Grumezescu

Received: 14 March 2021

Accepted: 6 April 2021

Published: 11 April 2021

Publisher's Note: MDPI stays neutral with regard to jurisdictional claims in published maps and institutional affiliations.

Copyright: (c) 2021 by the authors. Licensee MDPI, Basel, Switzerland. This article is an open access article distributed under the terms and conditions of the Creative Commons Attribution (CC BY) license (https:// creativecommons.org/licenses/by/ $4.0 /)$.

\begin{abstract}
As one of the common abiotic stresses, chilling stress has negative effects on rice growth and development. Minimization of these adverse effects through various ways is vital for the productivity of rice. Nanoparticles (NPs) serve as one of the effective alleviation methods against abiotic stresses. In our research, zinc oxide $(\mathrm{ZnO}) \mathrm{NPs}$ were utilized as foliar sprays on rice leaves to explore the mechanism underlying the effect of NPs against the negative impact of chilling stress on rice seedlings. We revealed that foliar application of ZnO NPs significantly alleviated chilling stress in hydroponically grown rice seedlings, including improved plant height, root length, and dry biomass. Besides, ZnO NPs also restored chlorophyll accumulation and significantly ameliorated chilling-induced oxidative stress with reduced levels of $\mathrm{H}_{2} \mathrm{O}_{2}$, MDA, proline, and increased activities of major antioxidative enzymes, superoxide dismutase (SOD), catalase (CAT), and peroxidase (POD). We further found that foliar application of $\mathrm{ZnO} N P s$ induced the chilling-induced gene expression of the antioxidative system (OsCu/ZnSOD1, OsCu/ZnSOD2, OsCu/ZnSOD3, OsPRX11, OsPRX65, OsPRX89, OsCATA, and OsCATB) and chilling response transcription factors (OsbZIP52, OsMYB4, OsMYB30, OsNAC5, OsWRKY76, and OsWRKY94) in leaves of chilling-treated seedlings. Taken together, our results suggest that foliar application of $\mathrm{ZnO}$ NPs could alleviate chilling stress in rice via the mediation of the antioxidative system and chilling response transcription factors.
\end{abstract}

Keywords: zinc oxide nanoparticles; chilling stress; rice; chilling response; antioxidative system

\section{Introduction}

Rice (Oryza sativa L.), a major crop in the world and the staple food for over half of the world's population, is mostly a tropical crop, but its distribution also extends to temperate and subtropical regions [1,2]. However, rice usually encounters environmental stresses such as extreme temperatures, drought, flooding, and high salinity [3], which greatly influence the growth and development of rice. Temperature is one of the vital factors for the production of rice, as the ideal temperature for rice growth ranges from 25 to $30{ }^{\circ} \mathrm{C}$ [4]. As previously reported, the growth and germination of the rice plant is negatively influenced when the temperature of the environment declines below $15^{\circ} \mathrm{C}$, and chilling stress that occurs below $20^{\circ} \mathrm{C}$ in the stages of grain-filling, booting, and flowering would result in an impossibility to grow rice on about $7 \times 10^{6}$ hectares of land in Southeast and South Asia [5-7]. Therefore, discovering the underlying mechanisms of the chilling response in rice will offer a theoretical basis for breeding chilling-tolerant varieties.

Chilling stress adversely affects the metabolic and physiological functions of rice, and thus reduces the yield [8,9]. The effects of chilling stress on rice growth and development involve different physiological pathways: affecting photosynthesis through the 
inhibition of chloroplast formation and chlorophyll biosynthesis in rice leaves [10]; inducing the accumulation of signal substances, e.g., malondialdehyde (MDA) and reactive oxygen species (ROS) [11,12]; accumulating compatible osmolytes, e.g., free proline [13] and impacting antioxidants, such as superoxide dismutase (SOD), catalase (CAT), and peroxidase (POD) $[14,15]$.

Besides, there are numerous transcription factors involved in the chilling response and tolerance of rice, including bZIP (basic leucine zipper), MYB (v-myb avian myeloblastosis viral oncogene homolog), NAC (NAM, ATAF, and CUC), and WRKY (tryptophan-argininelysine-tyrosine) [16]. A recent study revealed that one bZIP transcription factor, OsbZIP52, suppresses chilling resistance by inhibiting chilling-stress-related genes (e.g., OsTPP1) [16] Multiple studies reported that MYB transcription factors play a vital role in chilling tolerance. For instance, the R2R3-type OsMYB4 transcription factor regulates the rice chilling stress response independently via OsDREBs $[17,18]$. OsMYB30 inhibits the chilling tolerance by down-regulating the gene expression of $\beta$-AMYLASE (BMY) via interaction with JASMONATE ZIM-DOMAIN 9 (OsJAZ9) [19]. Moreover, a NAC transcription factor encoding gene, OsNAC5, enhances the tolerance of transgenic rice seedlings to chilling stress [20]. Furthermore, WRKY transcription factors, OsWRKY76 and OsWRKY94, confer chilling tolerance [21,22].

Minimization of chilling stress through various ways is vital for the productivity of rice. Nanoparticles (NPs) serve as an effective alleviation method against abiotic stresses. Advances in nanomaterials (NMs) can rise the production of crops in the present opposing environment. Present studies have shown that nanotechnology is able to enhance the development and growth of crops and alleviate the negative effects of abiotic stress [23]. Mohammadi et al. found that the application of $\mathrm{TiO}_{2} \mathrm{NPs}$ not only alleviated the membrane damage under cold stress but also prevented oxidative stress in chickpeas [24]. $\mathrm{TiO}_{2}$ treatment also increased the crop tolerance to cold stress via maintaining the stability of carotenoid and chlorophyll accumulations, inducing the activity of superoxide dismutase, ascorbate peroxidase, and catalase [25], and enhancing the gene expression of chlorophylland rubisco-binding proteins [26].

Nonetheless, previous studies have shown that ZnO NPs could alleviate abiotic stress (e.g., toxicity of cadmium) in plants [27], while the function of ZnO NPs in mitigating chilling stress is largely unknown. For this reason, we sprayed ZnO NPs to observe the effect of ZnO NPs on alleviating chilling stress in this research. Finally, we found that foliar application of ZnO NPs mitigated the chilling stress in hydroponically grown rice seedlings with induced chlorophyll accumulation and reduced oxidative stress. Potential underlying mechanisms of ZnO NPs on alleviation of chilling stress are also discussed.

\section{Results}

\subsection{Details of $\mathrm{ZnO} N \mathrm{NS}_{\mathrm{s}}$}

The NPs of $\mathrm{ZnO}$ were purchased from Chaowei Nano Technology Co., Ltd. (Shanghai, China). The particle morphology and size distribution of ZnO NPs were observed by transmission electron microscopy (TEM; Tecnai F20 S-TWIN, FEI Co., Hillsboro, OR, USA). The complete details of the ZnO NPs are shown in Table S1. The TEM images (Figure 1) revealed that the $\mathrm{ZnO} N P s$ were spherical with regular diameters of $30 \mathrm{~nm}$. The size distribution of the ZnO NPs in media (50 mg/L TX-10) with a concentration of $100 \mathrm{mg} / \mathrm{L}$ was determined with a Malvern Zetasizer (Nano ZS, Malvern, UK). To minimize agglomeration, we sonicated the different concentrations of $\mathrm{ZnO}$ NPs suspensions for $1 \mathrm{~h}$ before use. 


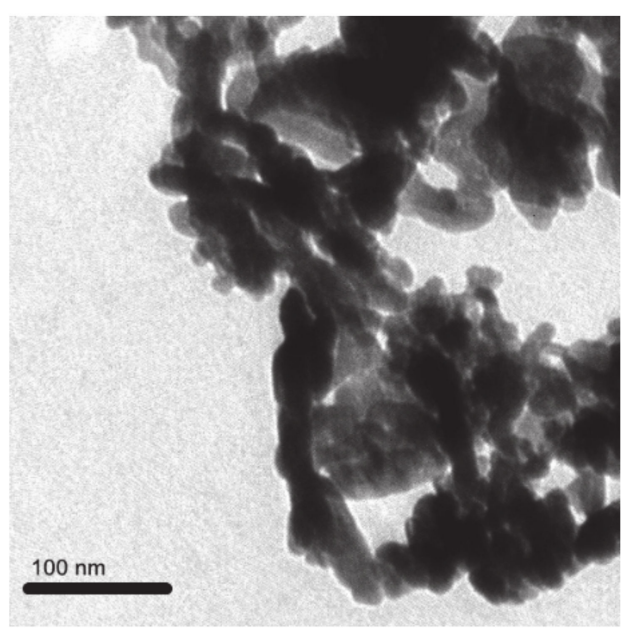

Figure 1. Characterization of the zinc oxide nanoparticles (ZnO NPs). Transmission electron microscopy (TEM) images of the ZnO NPs. Scale bars, $100 \mathrm{~nm}$.

\subsection{ZnO NPs Significantly Mitigated Chilling Stress in Rice}

To evaluate the effect of ZnO NPs application on chilling stress, 20-day-old rice plants were exposed to the chilling condition $\left(16 \mathrm{~h}\right.$ light $/ 8 \mathrm{~h}$ dark, at $\left.10^{\circ} \mathrm{C}\right)$. The low temperature $\left(10^{\circ} \mathrm{C}\right)$ caused toxicity in rice seedlings (Figure 2A). After 5 days of chilling stress treatment and 10 days of recovery, the plant height, root length, and dry biomass significantly decreased by $32.9 \%, 40.7 \%$, and $28.5 \%$, respectively compared with those of untreated control (Figure 2B-D). Rice seedlings also exhibited visible chlorosis in young leaves, and the content of total chlorophyll dramatically decreased by $40.4 \%$ after chilling stress treatment (Figure 3), compared to untreated control.

In contrast, the inhibition of growth of rice seedlings under chilling stress was alleviated after foliar application of ZnO NPs with different concentrations. The content of the $\mathrm{Zn}$ element in rice leaves was analyzed (Figure 4) after removal of $\mathrm{ZnO}$ NPs, which were physically adsorbed on the surfaces of leaves using a $\mathrm{KI} / \mathrm{I}_{2}$ solution. After the application of 25, 50, and $100 \mathrm{mg} / \mathrm{L} \mathrm{ZnO} \mathrm{NPs,} \mathrm{the} \mathrm{Zn} \mathrm{content} \mathrm{in} \mathrm{leaves} \mathrm{dramatically} \mathrm{increased,} \mathrm{namely}$ 42.5-, 20.3-, and 45.0-fold, compared to the application of $0 \mathrm{mg} / \mathrm{L} \mathrm{ZnO} \mathrm{NPs} \mathrm{under} \mathrm{chilling}$ stress (Figure 4). Similar results were displayed without chilling stress (Figure 4). The supplementation with ZnO NPs displayed a good performance in the alleviation of chilling stress in rice seedlings, which was reflected in a significantly higher value of plant height, root length, and dry biomass of rice plants. Moreover, by spraying with different concentrations of $\mathrm{ZnO} N \mathrm{Ns}$, the symptoms of chlorosis in rice leaves were significantly relieved and the accumulation of total chlorophyll was partially $(25 \mathrm{mg} / \mathrm{L})$ or totally (50 and $100 \mathrm{mg} / \mathrm{L}$ ) restored (Figure 3).

\subsection{Application of ZnO NPs Alleviated Chilling-Induced Oxidative Stress}

To further understand how $\mathrm{ZnO}$ NPs alleviated the chilling stress, we measured the contents of $\mathrm{H}_{2} \mathrm{O}_{2}, \mathrm{MDA}$, and proline, and the activities of antioxidant enzymes (SOD, CAT, and POD) in rice plants (Figures 5 and 6). On one hand, we found that chilling stress caused severe oxidative stress, as indicated by the increased ROS in non-radical form $\mathrm{H}_{2} \mathrm{O}_{2}$ (Figure $5 \mathrm{~A}$ ), which was severely toxic and caused serious damage to the plant cells. Chilling stress treatment strongly increased the levels of $\mathrm{H}_{2} \mathrm{O}_{2}, \mathrm{MDA}$, and proline in rice leaves by 2.42-, 2.60-, and 3.33-fold, respectively, compared to control (Figure 5). The supplementation of $100 \mathrm{mg} / \mathrm{L} \mathrm{ZnO} \mathrm{NPs} \mathrm{significantly} \mathrm{reduced} \mathrm{H}_{2} \mathrm{O}_{2}, \mathrm{MDA}$, and proline contents in leaves by $41.2 \%, 40.9 \%$, and $50.0 \%$, respectively, compared to single chilling stress (Figure 5). On the other hand, we found that chilling stress greatly reduced the antioxidant enzymes (SOD, CAT, and POD) activity in leaves by $45.8 \%, 41.6 \%$, and $47.7 \%$, respectively, compared to control (Figure 6). The application of $100 \mathrm{mg} / \mathrm{L} \mathrm{ZnO}$ NPs greatly 
increased the activities of SOD, CAT, and POD in chilling-treated rice seedlings compared to those under only chilling stress (Figure 6).
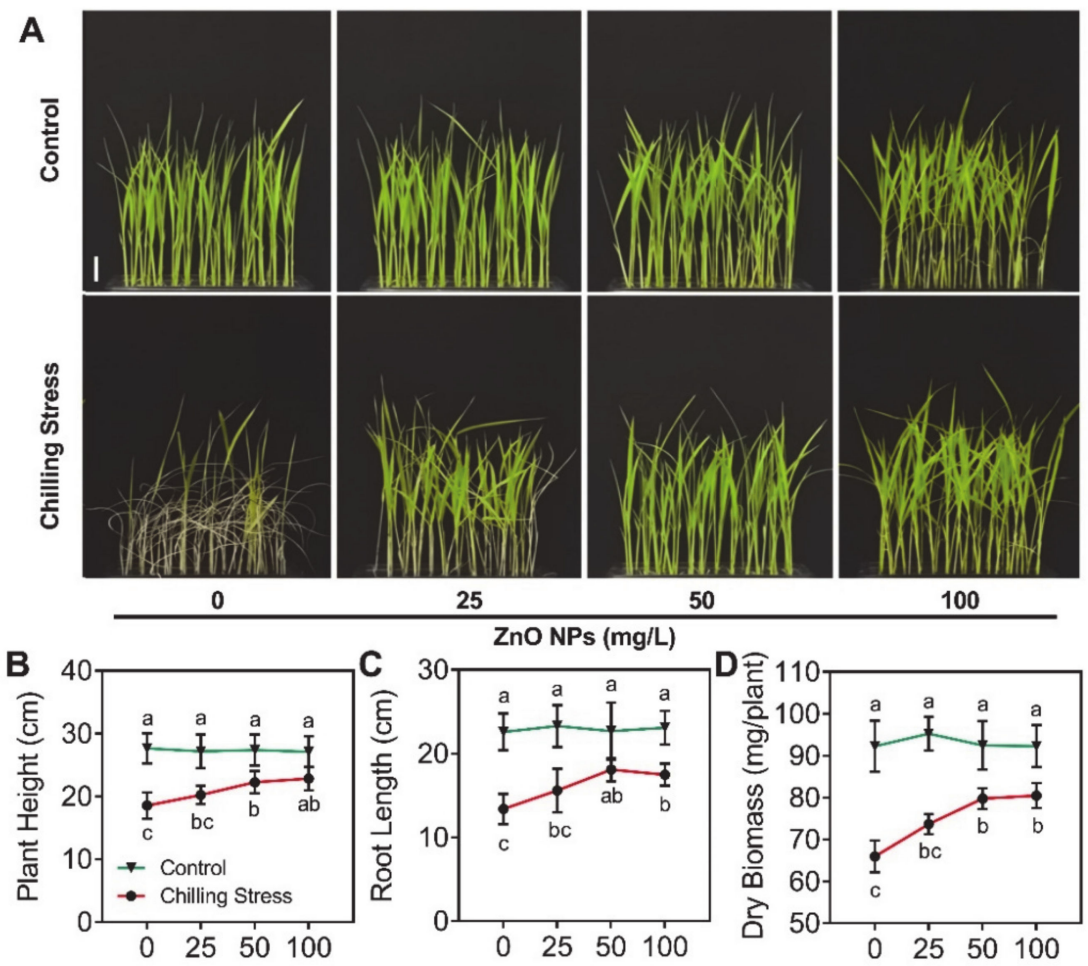

Figure 2. ZnO NPs alleviate chilling stress in rice. Phenotype (A), plant height (B), root length (C), and dry biomass (D) of rice seedlings subjected to $0,25,50$, and $100 \mathrm{mg} / \mathrm{L}$ of $\mathrm{ZnO}$ NPs under chilling stress were measured, respectively. The tests were repeated six times. The data given are the averages of six replicates, with the standard deviation (SD) shown by the error bars. Different letters above or below error bars show the differences at $p<0.05$. Scale bar $=5 \mathrm{~cm}(\mathbf{A})$.
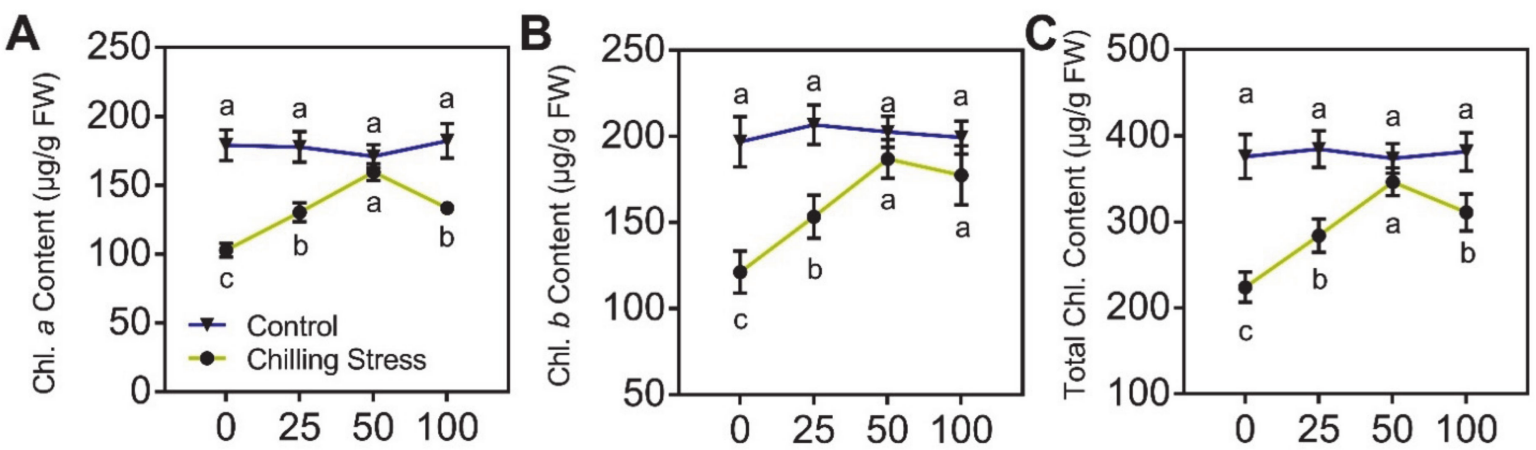

Figure 3. Effects of ZnO NPs on the content of chlorophyll (Chl.) in rice seedlings under chilling stress. Chl. $a(\mathbf{A}), \mathrm{Chl} . b$ (B), and total Chl. (C) in leaves of rice seedlings subjected to $0,25,50$, and $100 \mathrm{mg} / \mathrm{L}$ of ZnO NPs under chilling stress were measured, respectively. The tests were repeated three times. The data given are the averages of three replicates, with the standard deviation (SD) shown by the error bars. Different letters above or below error bars show the differences at $p<0.05$. FW, fresh weight. 


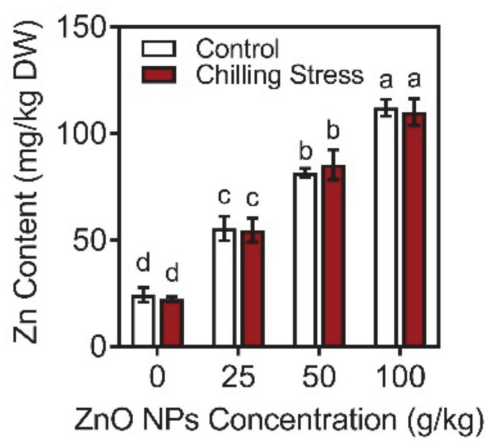

Figure 4. $\mathrm{Zn}$ accumulation in rice leaves. $\mathrm{Zn}$ accumulation of rice seedlings subjected to 0 , 25, 50, and $100 \mathrm{mg} / \mathrm{L}$ of ZnO NPs under chilling stress were measured, respectively. The tests were repeated three times. The data given are the averages of three replicates, with the SD shown by the error bars. Different letters above error bars show the differences at $p<0.05$. DW, dry weight.
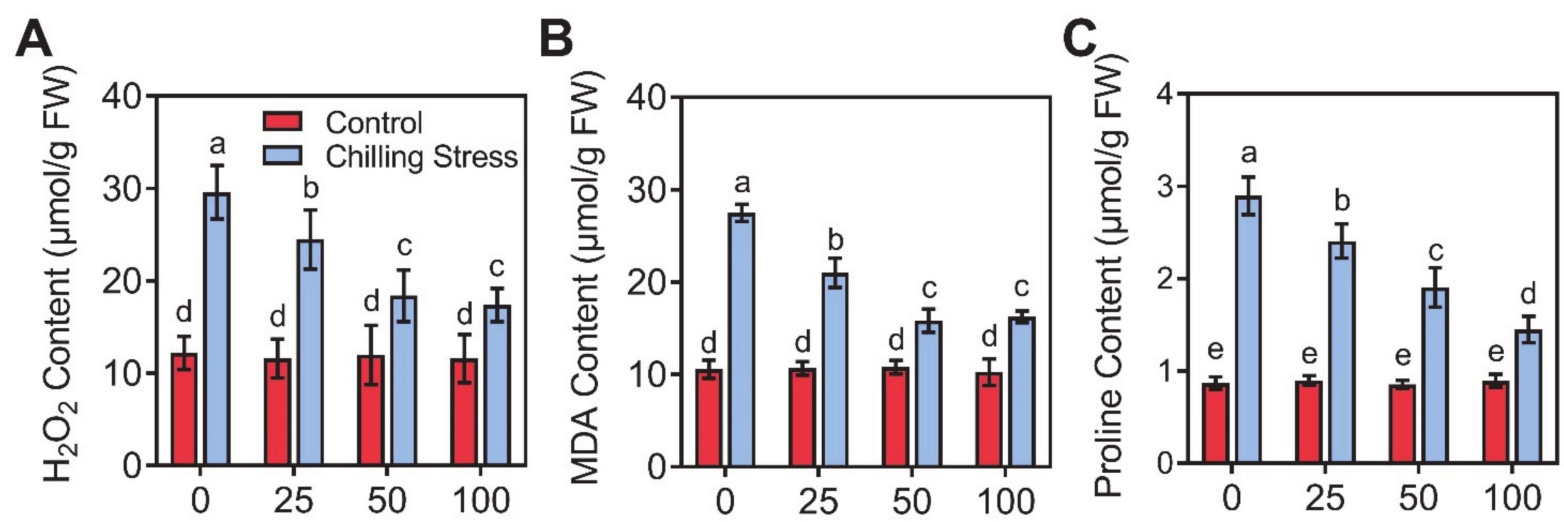

Figure 5. Effects of ZnO NPs on oxidative damage in rice leaves under chilling stress. Hydrogen peroxide $\left(\mathrm{H}_{2} \mathrm{O}_{2}, \mathbf{A}\right)$, malondialdehyde (MDA, B), and proline (C) of rice seedlings subjected to 0, 25, 50, and $100 \mathrm{mg} / \mathrm{L}$ of ZnO NPs under chilling stress were measured, respectively. The tests were repeated three times. The data given are the averages of three replicates, with the SD shown by the error bars. Different letters above error bars show the differences at $p<0.05$. FW, fresh weight.
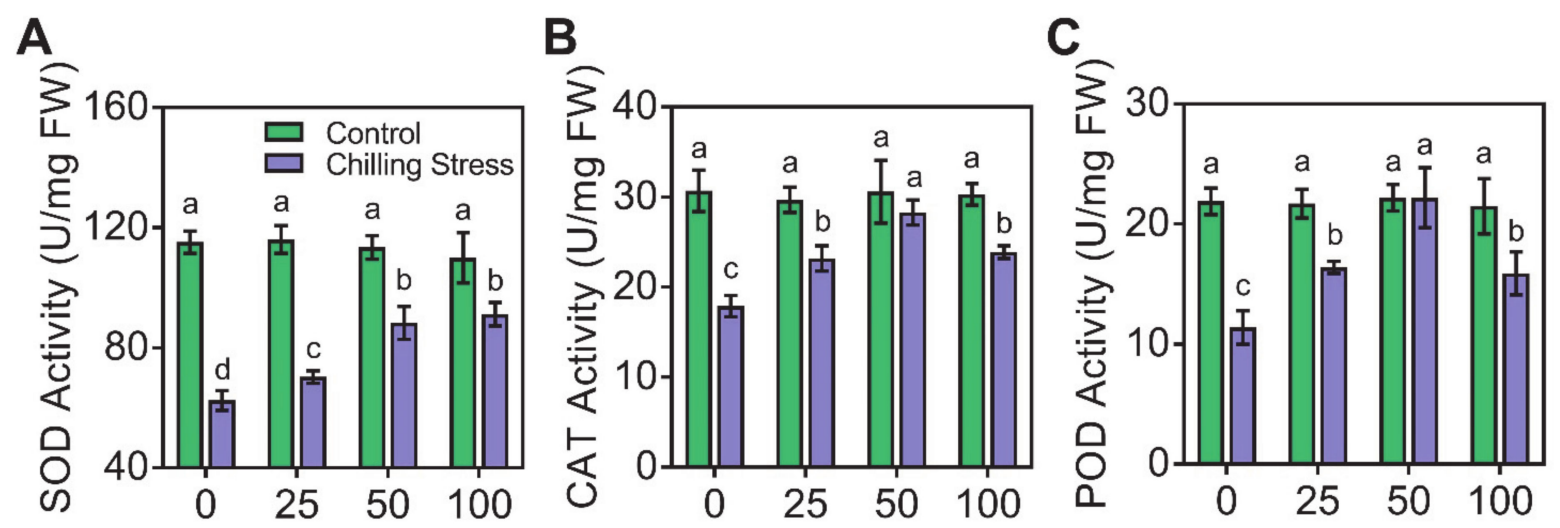

Figure 6. Effects of ZnO NPs on antioxidant enzyme activity in rice leaves under chilling stress. Superoxide dismutase (SOD, A), catalase (CAT, B), and peroxidase (POD, C) of rice seedlings subjected to 0, 25, 50, and $100 \mathrm{mg} / \mathrm{L}$ of $\mathrm{ZnO} \mathrm{NPs}$ under chilling stress were measured, respectively. The tests were repeated three times. The data given are the averages of three replicates, with the SD shown by the error bars. Different letters above error bars show the differences at $p<0.05$. FW, fresh weight. 
To investigate the molecular basis of how $\mathrm{ZnO}$ NPs reduces oxidative stress in rice, the gene expression of antioxidant enzymes containing OsCu/ZnSOD1, OsCu/ZnSOD2, OsCu/ZnSOD3, OsPRX11, OsPRX65, OsPRX89, OsCATA, and OsCATB was measured. Chilling stress significantly decreased the gene expression of antioxidant enzymes (SOD, CAT, and POD) compared to control (Figure 7 and Figure S1), while the application of different concentrations of $\mathrm{ZnO}$ NPs greatly increased the gene expression of SOD, CAT, and POD, in chilling-treated rice plants compared to only chilling stress (Figure 7 and Figure S1). These results indicated that $\mathrm{ZnO}$ NPs application could relieve oxidative stress in rice seedlings exposed to chilling stress by reducing ROS and enhancing the expression of antioxidant enzymes.
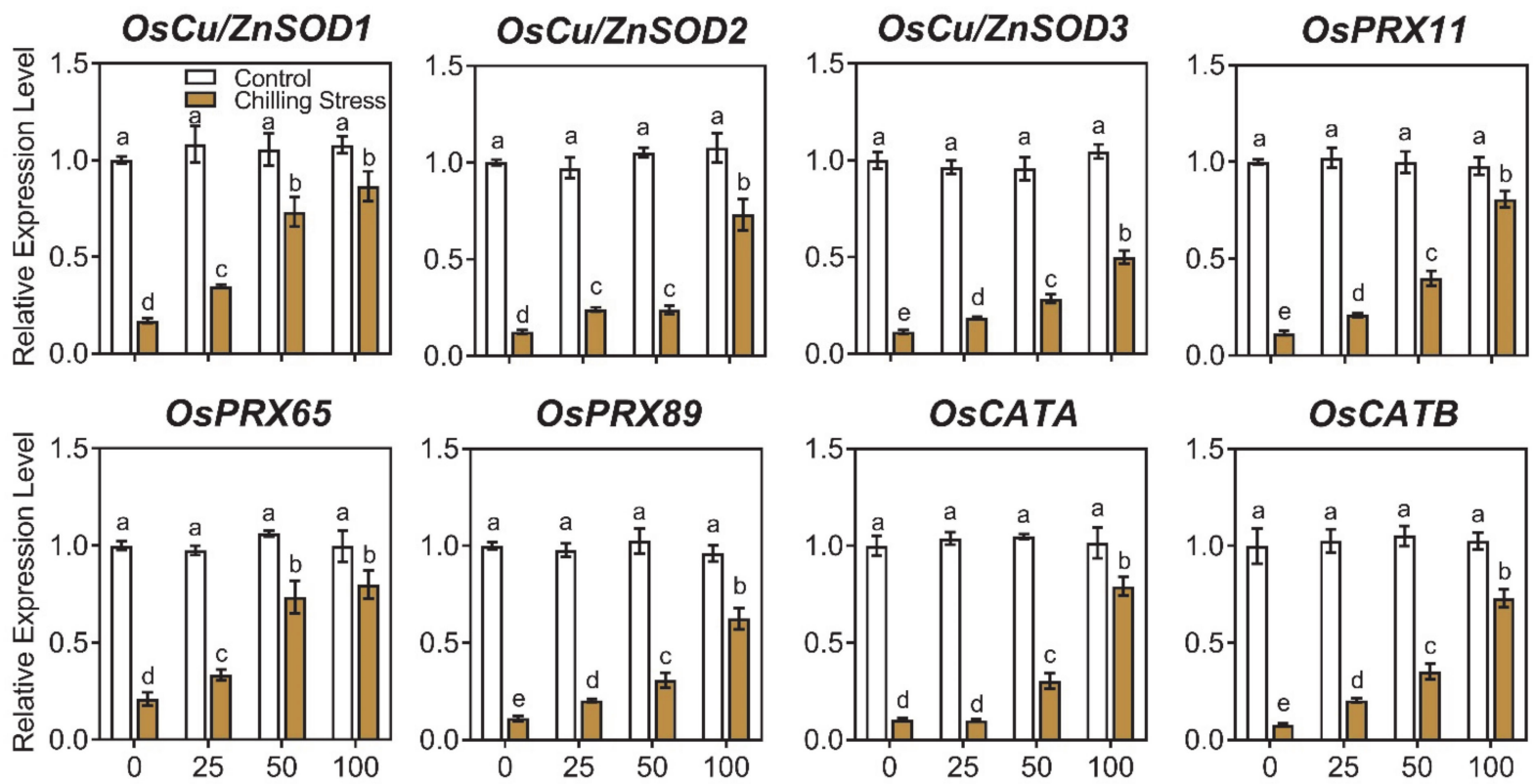

Figure 7. Effects of ZnO NPs on gene expression of antioxidant enzymes in rice leaves under chilling stress. Gene expression of rice seedlings subjected to $0,25,50$, and $100 \mathrm{mg} / \mathrm{L}$ of $\mathrm{ZnO}$ NPs under chilling stress was measured, respectively. Gene expression was first normalized to the UBQ5 gene in rice as an internal control and executed relative to each gene's expression of control (assigned a value of 1). The data given are the averages of three replicates, with the SD shown by the error bars. Different letters above error bars show the differences at $p<0.05$.

\subsection{ZnO NPs Reduced Gene Expression of Chilling Response Transcription Factors under Chilling Stress in Rice}

To investigate the molecular basis of how $\mathrm{ZnO} N P s$ alleviates chilling stress in rice, the genes of chilling response transcription factors including OsbZIP52, OsMYB4, OsMYB30, OsNAC5, OsWRKY76, and OsWRKY94 were chosen for gene expression analysis in rice leaves (Figure 8 and Figure S2). Exposure to chilling stress significantly induced the expression of OsbZIP52, OsMYB4, OsMYB30, OsNAC5, OsWRKY76, and OsWRKY94 in rice leaves. Application of $\mathrm{ZnO}$ NPs restored the expression of all above-mentioned genes to control level after chilling stress in rice leaves (Figure 8 and Figure S2). These results demonstrated that the reduced gene expression of the chilling response may be an important mechanism for the ZnO NPs-produced alleviation. 

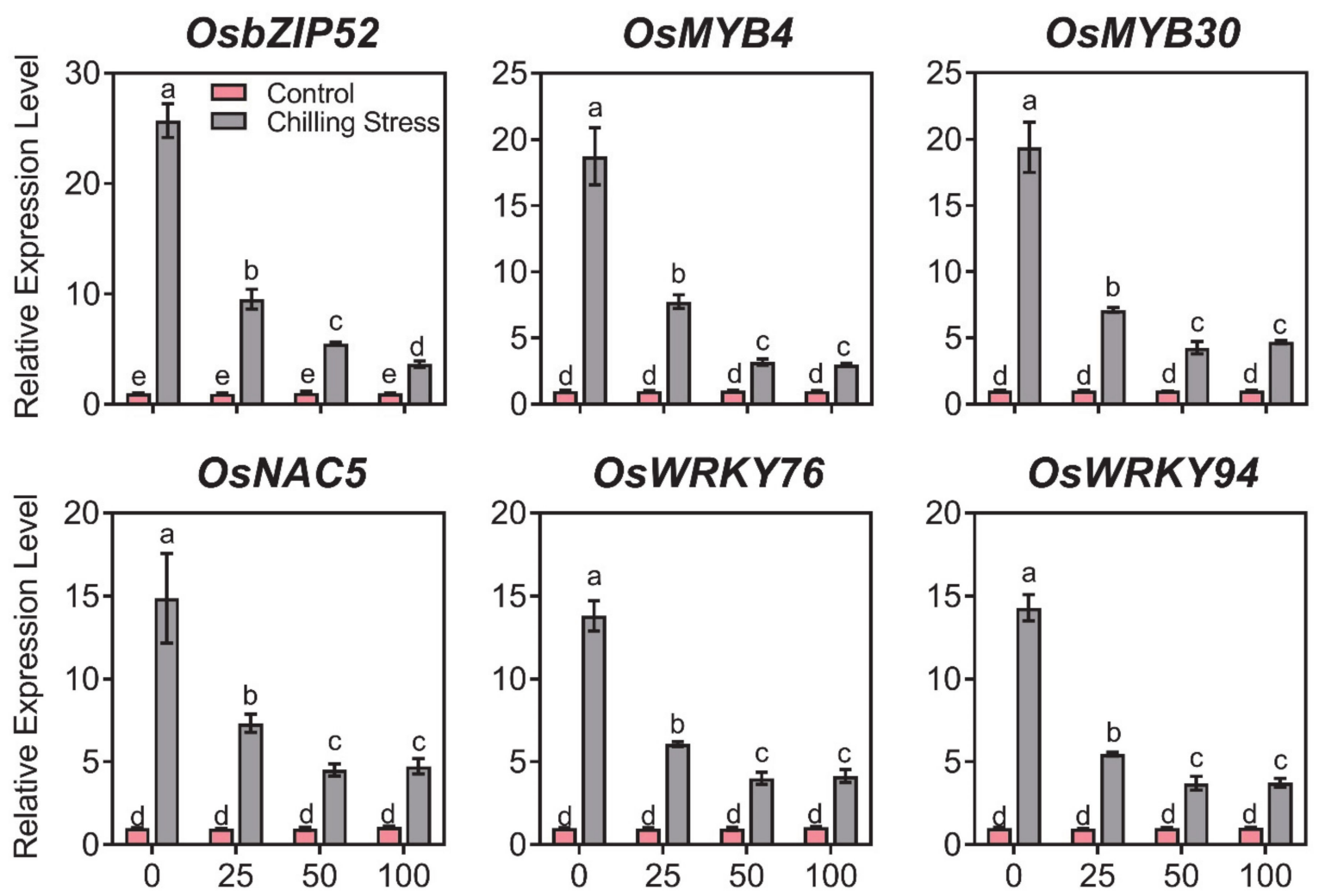

Figure 8. Effects of ZnO NPs on gene expression of chilling response transcription factors in rice leaves under chilling stress. Gene expression of rice seedlings subjected to 0, 25, 50, and $100 \mathrm{mg} / \mathrm{L}$ of ZnO NPs under chilling stress was measured, respectively. Gene expression was first normalized to the UBQ5 gene in rice as an internal control and executed relative to each gene's expression of control (assigned a value of 1 ). The data given are the averages of three replicates, with the SD shown by the error bars. Different letters above error bars show the differences at $p<0.05$.

\section{Discussion}

Applications of ZnO NPs to resistance to stresses (drought stress, salinity stress, cadmium and lead toxicity) have been reported in several plants. The supplementation of $\mathrm{ZnO}$ NPs increased the seed germination percentage and rate, and decreased the seed fresh and dry weight of soybean (Glycine max L.) under drought stress [28]. Besides, under salinity stress, feeding with ZnO NPs also greatly improve plant growth and development in sunflower (Helianthus annuus L.) [29] and wheat (Triticum aestivum L.) [30]. Also, ZnO NPs alleviated cadmium $(\mathrm{Cd})$ toxicity in wheat by enhancing wheat growth and $\mathrm{Zn}$ concentrations, while reducing the $\mathrm{Cd}$ concentration in plants [27]. ZnO NPs alleviated the bioavailability of cadmium and lead and changed the uptake of iron in hydroponically grown lettuce (Lactuca sativa L.) [31]. However, no related research has reported the effects of ZnO NPs on rice seedlings under chilling stress. In this study, we found that foliar application of ZnO NPs efficiently mitigated chilling stress in rice seedlings. In particular, $\mathrm{ZnO}$ NPs application significantly increased the resistance to chilling stress in rice by restoring chlorophyll biosynthesis, reducing the level of ROS, enhancing the activity of antioxidant enzymes, and regulating the gene expression of chilling stress response transcription factors.

Firstly, to confirm that the ZnO NPs were absorbed by rice plants, we measured the content of $\mathrm{Zn}$ element in rice leaves with different treatments (Figure 4). Consistent with previous reports on plants [32,33], our results revealed that the accumulation of ZnO NPs greatly increased under both control and chilling stress conditions in rice seedlings with different supplements of $\mathrm{ZnO}$ NPs (Figure 4), while there was no difference in the content of $\mathrm{Zn}$ element between control and chilling stress treatment under different supplements 
of $\mathrm{ZnO}$ NPs (Figure 4). These results demonstrated that with the increase in the amount of $\mathrm{ZnO}$ NPs sprayed, the $\mathrm{Zn}$ concentration in the organs of rice leaves increased but was not affected by chilling stress.

Chilling stress adversely affects the metabolic and physiological functions of rice, and thus reduces the yield $[8,9,34,35]$. Chilling stress impacts rice growth and development by affecting photosynthesis, with the inhibition of chloroplast formation and chlorophyll biosynthesis in rice leaves [10,36,37]. Similar to previous studies, rice seedlings also exhibited visible chlorosis in young leaves, and the content of total chlorophyll (chlorophyll $a$ and $b$ ) was significantly reduced after the chilling stress treatment (Figure 3) compared to untreated control. Furthermore, by spraying with ZnO NPs, the symptoms of chlorosis in rice leaves were significantly relieved, and the accumulation of total chlorophyll was restored (Figure 3).

The oxidative bursts produced by chilling stress can induce the accumulation of signal substances, e.g., malondialdehyde (MDA) and reactive oxygen species (ROS) [11,12]; accumulate compatible osmolytes, e.g., free proline [13] and impact antioxidants, such as superoxide dismutase (SOD), catalase (CAT), and peroxidase (POD) [14,15]. However, the responses change in different higher plants and display dose-, tissue-, development-, and genotype-dependency [38]. The activity of CAT in rice markedly decreased, and the contents of $\mathrm{H}_{2} \mathrm{O}_{2}$ and MDA greatly increased, by chilling stress treatment compared to control [15]. The activity of SOD and CAT in some varieties of rice seedlings displayed small changes due to chilling stress, and other varieties of rice showed greatly reduced levels; however, the contents of $\mathrm{H}_{2} \mathrm{O}_{2}$ and MDA increased under chilling stress in most tested varieties of rice [39]. In our research, the activity of all of the antioxidant enzymes measured reduced after chilling stress (Figure 6), which was similar to the reports of Sohag et al. [15] and Wang et al. [39]. The gene expression of antioxidant enzymes containing OsCu/ZnSOD1, OsCu/ZnSOD2, OsCu/ZnSOD3, OsPRX11, OsPRX65, OsPRX89, OsCATA, and OsCATB was also induced with the application of ZnO NPs under chilling stress (Figure 7). Reduced SOD, CAT, and POD activity and gene expression might lead to an oxidative burst after chilling stress in rice seedlings, as revealed by the ROS level, such as $\mathrm{H}_{2} \mathrm{O}_{2}$ in chilling-treated rice, and finally caused induced lipid peroxidation, e.g., MDA (Figures 5-7). Foliar application of ZnO NPs alleviated chilling-produced oxidative stress by enhancing antioxidant enzyme activity and reducing ROS content in rice seedlings. The oxidative stress was greatly mitigated by ZnO NPs, demonstrating that improving the antioxidant defense capacity may be an important mechanism for the $\mathrm{ZnO}$ NPs-produced alleviation.

Different transcription factors involved in the chilling tolerance and chilling response in rice, namely OsbZIP52 [16], OsMYB4 [17,18], OsMYB30 [19], OsNAC5 [20], OsWRKY76 [21], and OsWRKY94 [22], were reported to be greatly induced under chilling stress in related studies. In this study, all the above chilling response genes tested increased under chilling stress (Figure 8), which was similar to the former reports [16-22]. ZnO NPs reduced the expression of these chilling-stress-induced response genes, thereby alleviating various toxicities caused by chilling stress. Foliar application of ZnO NPs decreased the gene expression of the chilling response in rice seedlings, which demonstrated that the reduced gene expression of the chilling response may be an important mechanism for the ZnO NPs-produced alleviation.

In conclusion, we demonstrated that foliar application of ZnO NPs could efficiently mitigate the toxicity of chilling stress in rice. In particular, ZnO NPs significantly reduced the toxicity of chilling stress in rice leaves by regulating the gene expression of chilling stress response transcription factors, indicating ZnO NPs played a vital role in regulating the chilling response. ZnO NPs also had influential and multiple effects on plant growth and chlorophyll biosynthesis, finally enhancing the antioxidant potential and the abilities of ROS scavenging under chilling stress. Therefore, our findings not only illustrate the effect and mechanism of ZnO NPs in suppressing the toxicity of chilling stress in rice, but also provide a practicable solution for reducing chilling stress effects on crops. 


\section{Materials and Methods}

\subsection{Plant Materials and Treatments}

The seeds of rice (Oryza sativa ssp Japonica cultivar Nipponbare) were sterilized with $20 \%(v / v) \mathrm{NaClO}$ and then soaked in ultrapure water at $30{ }^{\circ} \mathrm{C}$ for 2 days. A total of 48 rice seeds were then transplanted into 96-well plastic hydroponic boxes including $1 / 2$ Murashige-Skoog (MS) standard liquid medium, and planted in a growth chamber with $75 \%$ relative humidity (normal condition: $16 \mathrm{~h}$ light at $30^{\circ} \mathrm{C} / 8 \mathrm{~h}$ dark at $25^{\circ} \mathrm{C}$ ). For the foliage $\mathrm{ZnO}$ NPs spraying, 10-day-old rice plants grown in diverse boxes including $1 / 2 \mathrm{MS}$ standard liquid medium under the normal condition were sprayed $50 \mathrm{~mL} \mathrm{ZnO}$ NPs solution (25, 50, and $100 \mathrm{mg} / \mathrm{L}$ ZnO NPs with $50 \mathrm{mg} / \mathrm{L} \mathrm{TX-10)}$ daily for 10 days. The $50 \mathrm{mg} / \mathrm{L}$ TX-10 replicates were utilized as controls. For the chilling stress treatment, 20-day-old rice plants were placed under the chilling condition $(16 \mathrm{~h}$ light $/ 8 \mathrm{~h}$ dark, at $10{ }^{\circ} \mathrm{C}$ ) for 5 days. Then, the chilling-treated rice seedlings were moved to the normal condition for 1 week. The 32-day-old rice seedlings with or without ZnO NPs treatment were sampled for phenotypical, physiological, and molecular detections. Six replicates (the replicates here correspond to one plant) were tested for the measurements of plant height, root length, and dry biomass, and three replicates (the replicates here correspond to three to six plants depending on the weight) were detected for other molecular, physiological, and biochemical measurements.

\subsection{Measurement of Zinc ( $\mathrm{Zn})$ Content}

The concentration of $Z n$ in rice leaves was measured according to a previous method [40]. Briefly, $\mathrm{Zn}$ absorbed on the surface of seedlings was eliminated by immersing the root in $20 \mathrm{mM} \mathrm{Na}_{2}$-EDTA (disodium ethylenediamine tetra-acetic acid) for $60 \mathrm{~min}$, and then rinsing five times with distilled water. The sample of rice was dried at $105^{\circ} \mathrm{C}$ for $120 \mathrm{~min}$ and at $60^{\circ} \mathrm{C}$ for $48 \mathrm{~h}$. The weight of whole seedlings was measured as dry biomass after reaching an unchanging weight. Dried plant samples (about $0.1 \mathrm{~g}$ ) were mixed with $6 \mathrm{~mL}$ of $\mathrm{HNO}_{3}$ and kept in the reaction with a Multiwave (MARS 6, CEM Co., Matthews, NC, USA) at $140{ }^{\circ} \mathrm{C}$ for about $2 \mathrm{~h}$. Finally, the content of $\mathrm{Zn}$ was measured with the atomic absorption spectrometer AA-7000 (Shimadzu, Tokyo, Japan).

\subsection{Determination of Chlorophyll (Chl.)}

The content of Chl. in rice leaves was quantified as previously reported [41]. About $100 \mathrm{mg}$ of fresh rice leaves were mixed and ground with $10 \mathrm{~mL} 80 \%(v / v)$ acetone. After being kept in darkness for $2 \mathrm{~h}$, the mixture was centrifuged at $12,000 \times \mathrm{g}$ for $10 \mathrm{~min}$. Finally, the absorbance at 663 and $645 \mathrm{~nm}$ was measured, respectively.

\subsection{Hydrogen Peroxide $\left(\mathrm{H}_{2} \mathrm{O}_{2}\right)$ Detection}

The $\mathrm{H}_{2} \mathrm{O}_{2}$ content was measured using a hydrogen peroxide assay kit (Solarbio, Beijing, China) [42]. The content of $\mathrm{H}_{2} \mathrm{O}_{2}$ in rice leaves was detected by measuring the absorbance of titanium-peroxide complex formation at $415 \mathrm{~nm}$.

\subsection{Measurement of Malondialdehyde (MDA) Content}

The accumulation of MDA was determined following a previously described protocol [43]. Approximately $100 \mathrm{mg}$ of rice leaves were homogenized and mixed with $10 \mathrm{~mL} 10 \%(v / v)$ of trichloroacetic acid, and the mixture was then centrifuged at top speed $(12,000 \times g)$ for $20 \mathrm{~min}$. The supernatant was mixed with an equal volume of thiobarbituric acid and then kept at $95^{\circ} \mathrm{C}$ for $30 \mathrm{~min}$. The mixture was centrifuged at $12,000 \times g$ for $30 \mathrm{~min}$ after being quickly cooled on ice, and the supernatant absorbance at 450,532, and $600 \mathrm{~nm}$ was measured, respectively.

\subsection{Measurement of Free Proline (Pro)}

The content of free proline was measured as previously reported [44]. About $1 \mathrm{~g}$ of rice leaves were ground with an aqueous solution of $3 \%(v / v)$ sulfosalicylic acid. After 
centrifugation at room temperature at $12,000 \times g$ for $15 \mathrm{~min}, 2 \mathrm{~mL}$ of supernatant was added to the same volumes of glacial acetic acid and acidic ninhydrin. This mixture was heated at $95{ }^{\circ} \mathrm{C}$ for $40 \mathrm{~min}$, cooled on ice, and then followed by the addition of $4 \mathrm{~mL}$ of toluene to extract the colored reaction product separated from the aqueous phase. The absorbance of the toluene phase at $520 \mathrm{~nm}$ was determined, and the standard curve of proline was utilized to assay the accumulation of free proline.

\subsection{Antioxidant Enzyme Activities Determination}

The activity of the antioxidant enzymes containing superoxide dismutase (SOD), catalase (CAT), and peroxidase (POD) was measured using respective commercial kits (Solarbio, Beijing, China) as previously published [45-47]. The standardization of antioxidant enzymes activity was described: one unit of SOD activity was expressed as the suppression of photoreduction of 4-nitro blue tetrazolium chloride (NBT) by half under light; one unit of CAT activity was detected according to the decomposition of $1 \mathrm{nmol} \mathrm{H}_{2} \mathrm{O}_{2}$ per min; one unit of POD activity was assayed by determining an absorbance (470 $\mathrm{nm})$ increase of 0.01 per min.

\subsection{Gene Expression Assay}

Relative gene expression was determined as previously published $[48,49]$. The RNAprep Pure Plant Kit (Tiangen, Beijing, China) and HiScript III 1st Strand cDNA Synthesis Kit (Vazyme Biotech Co., Ltd., Nanjing, China) were used to extract and reversetranscribe the total RNA from rice leaves. AceQ qPCR SYBR Green Master Mix (Vazyme, Nanjing, China) was used to apply the quantitative real-time PCR (qRT-PCR). The qRT-PCR primers are listed in Table S2. The ACTIN gene in rice was used as an internal control (Table S2), and the level of gene expression was measured following the method of $2^{-\Delta \Delta \mathrm{Ct}}$ [50].

\subsection{Statistical Analyses}

The data in the figures and tables is presented as means with standard deviation (SD) because there were six or three replications. The mean differences were assessed using ANOVA. The statistical significance of differences between treatments was assessed using Bonferroni post-hoc tests.

Supplementary Materials: The following are available online. Figure S1: Expression profiles of antioxidant enzymes genes in rice leaves, Figure S2: Expression profiles of chilling response transcription factors genes in rice leaves, Table S1: Characterization details of ZnO NPs, Table S2: Primers used in the present study.

Author Contributions: Conceptualization, Y.S. and R.L.; methodology, M.J. and R.L.; software, H.Z.; validation, H.Z.; formal analysis, Y.S. and R.L.; investigation, Y.S., M.J., and R.L.; resources, R.L.; data curation, Y.S. and R.L.; writing—original draft preparation, Y.S.; writing-review and editing, M.J. and R.L.; visualization, M.J. and R.L.; supervision, R.L.; project administration, R.L.; funding acquisition, R.L. All authors have read and agreed to the published version of the manuscript.

Funding: This research was funded by the Natural Foundation of Anhui Province (grant number: 1908085QC103), the Open Project Program of State Key Laboratory of Rice Biology (grant number: 20200104), Funding of Introduction \& Stability for Talents supported by Anhui Agricultural University (grant number: yj2018-39), Postdoctoral Science Foundation of Zhejiang Province (grant number: ZJ2020157), and China Postdoctoral Science Foundation (grant number: 2020M680078).

Institutional Review Board Statement: Not applicable.

Informed Consent Statement: Not applicable.

Data Availability Statement: The data presented in this study are available in the article or Supplementary Materials.

Conflicts of Interest: The authors declare no conflict of interest.

Sample Availability: Samples of the compounds are not available from the authors. 


\section{References}

1. Sasaki, T.; Burr, B. International rice genome sequencing project: The effort to completely sequence the rice genome. Curr. Opin. Plant Biol. 2000, 3, 138-141. [CrossRef]

2. Kovach, M.J.; Sweeney, M.T.; McCouch, S.R. New insights into the history of rice domestication. Trends Genet. 2007, 23, 578-587. [CrossRef]

3. Cramer, G.R.; Urano, K.; Delrot, S.; Pezzotti, M.; Shinozaki, K. Effects of abiotic stress on plants: A systems biology perspective. BMC Plant Biol. 2011, 11, 163. [CrossRef]

4. Zhang, Q.; Chen, Q.; Wang, S.; Hong, Y.; Wang, Z. Rice and cold stress: Methods for its evaluation and summary of cold tolerance-related quantitative trait loci. Rice 2014, 7, 24. [CrossRef] [PubMed]

5. Sales, E.; Viruel, J.; Domingo, C.; Marques, L. Genome wide association analysis of cold tolerance at germination in temperate japonica rice (Oryza sativa L.) varieties. PLoS ONE 2017, 12, e0183416. [CrossRef] [PubMed]

6. Liu, C.T.; Wang, W.; Mao, B.G.; Chu, C.C. Cold stress tolerance in rice: Physiological changes, molecular mechanism, and future prospects. Hereditas (Beijing) 2018, 40, 171-185. (In Chinese) [PubMed]

7. Sthapit, B.R.; Witcombe, J.R. Inheritance of tolerance to chilling stress in rice during germination and plumule greening. Crop Sci. 1998, 38, 660-665. [CrossRef]

8. Ma, Q.; Dai, X.; Xu, Y.; Guo, J.; Liu, Y.; Chen, N.; Xiao, J.; Zhang, D.; Xu, Z.; Zhang, X.; et al. Enhanced tolerance to chilling stress in OsMYB3R-2 transgenic rice is mediated by alteration in cell cycle and ectopic expression of stress genes. Plant Physiol. 2009, 150, 244-256. [CrossRef] [PubMed]

9. Arshad, M.S.; Farooq, M.; Asch, F.; Krishna, J.S.V.; Prasad, P.V.V.; Siddique, K.H.M. Thermal stress impacts reproductive development and grain yield in rice. Plant Physiol. Biochem. 2017, 115, 57-72. [CrossRef] [PubMed]

10. Yang, J.C.; Li, M.; Xie, X.Z.; Han, G.; Sui, N.; Wang, B.S. Deficiency of phytochrome B alleviates chilling-induced photoinhibition in rice. Am. J. Bot. 2013, 100, 1860-1870. [CrossRef]

11. Sato, Y.; Masuta, Y.; Saito, K.; Murayama, S.; Ozawa, K. Enhanced chilling tolerance at the booting stage in rice by transgenic overexpression of the ascorbate peroxidase gene, OsAPXa. Plant Cell Rep. 2011, 30, 399-406. [CrossRef]

12. Xie, G.; Kato, H.; Imai, R. Biochemical identification of the OsMKK6-OsMPK3 signalling pathway for chilling stress tolerance in rice. Biochem. J. 2012, 443, 95-102. [CrossRef]

13. Huang, J.; Sun, S.; Xu, D.; Lan, H.; Sun, H.; Wang, Z.; Bao, Y.; Wang, J.; Tang, H.; Zhang, H. A TFIIIA-type zinc finger protein confers multiple abiotic stress tolerances in transgenic rice (Oryza sativa L.). Plant Mol. Biol. 2012, 80, 337-350.

14. Lu, X.; Zhou, Y.; Fan, F.; Peng, J.H.; Zhang, J. Coordination of light, circadian clock with temperature: The potential mechanisms regulating chilling tolerance in rice. J. Integr. Plant Biol. 2019, 62, 737-760. [CrossRef] [PubMed]

15. Sohag, A.A.M.; Tahjib-Ul-Arif, M.; Afrin, S.; Khan, M.K.; Hannan, M.A.; Skalicky, M.; Mortuza, M.G.; Brestic, M.; Hossain, M.A.; Murata, Y. Insights into nitric oxide-mediated water balance, antioxidant defence and mineral homeostasis in rice (Oryza sativa L.) under chilling stress. Nitric Oxide 2020, 100, 7-16. [CrossRef] [PubMed]

16. Liu, C.; Wu, Y.; Wang, X. bZIP transcription factor OsbZIP52/RISBZ5: A potential negative regulator of cold and drought stress response in rice. Planta 2012, 235, 1157-1169. [CrossRef] [PubMed]

17. Park, M.R.; Yun, K.Y.; Mohanty, B.; Herath, V.; Xu, F.; Wijaya, E.; Bajic, V.B.; Yun, S.J.; De Los Reyes, B.G. Supraoptimal expression of the cold-regulated OsMyb4 transcription factor in transgenic rice changes the complexity of transcriptional network with major effects on stress tolerance and panicle development. Plant Cell Environ. 2010, 33, 2209-2230. [CrossRef]

18. Tominaga-Wada, R.; Nukumizu, Y. Expression analysis of an R3-Type MYB transcription factor CPC-LIKE MYB4 (TRICHOMELESS2) and CPL4-Related transcripts in Arabidopsis. Int. J. Mol. Sci. 2012, 13, 3478-3491.

19. Lv, Y.; Yang, M.; Hu, D.; Yang, Z.; Ma, S.; Li, X.; Xiong, L. The OsMYB30 transcription factor suppresses cold tolerance by interacting with a JAZ protein and suppressing betaamylase expression. Plant Physiol. 2017, 173, 1475-1491. [CrossRef]

20. Song, S.Y.; Chen, Y.; Chen, J.; Dai, X.Y.; Zhang, W.H. Physiological mechanisms underlying OsNAC5-dependent tolerance of rice plants to abiotic stress. Planta 2011, 234, 331-345. [CrossRef]

21. Yokotani, N.; Sato, Y.; Tanabe, S.; Chujo, T.; Shimizu, T.; Okada, K.; Yamane, H.; Shimono, M.; Sugano, S.; Takatsuji, H.; et al. WRKY76 is a rice transcriptional repressor playing opposite roles in blast disease resistance and cold stress tolerance. J. Exp. Bot. 2013, 64, 5085-5097. [CrossRef]

22. Chen, L.; Zhao, Y.; Xu, S.; Zhang, Z.; Xu, Y.; Zhang, J.; Chong, K. OsMADS57 together with OsTB1 coordinates transcription of its target OsWRKY94 and D14 to switch its organogenesis to defense for cold adaptation in rice. New Phytol. 2018, 218, $219-231$. [CrossRef]

23. Shang, Y.; Hasan, M.K.; Ahammed, G.J.; Li, M.; Yin, H.; Zhou, J. Applications of nanotechnology in plant growth and crop protection: A review. Molecules 2019, 24, 2558.

24. Mohammadi, R.; Amiri, N.M.; Mantri, L. Effect of $\mathrm{TiO}_{2}$ nanoparticles on oxidative damage and antioxidant defense systems in chickpea seedlings during cold stress. Russ. J. Plant Physiol. 2013, 61, 768-775. [CrossRef]

25. Mohammadi, H.; Esmailpour, M.; Gheranpaye, A. Effects of $\mathrm{TiO}_{2}$ nanoparticles and water-deficit stress on morpho-physiological characteristics of dragonhead (Dracocephalum moldavica L.) plants. Environ. Toxicol. Chem. 2014, 33, 2429-2437. [CrossRef]

26. Hasanpour, H.; Maali-Amiri, R.; Zeinali, H. Effect of $\mathrm{TiO}_{2}$ nanoparticles on metabolic limitations to photosynthesis under cold in chickpea. Russ. J. Plant Physiol. 2015, 62, 779-787. 
27. Hussain, A.; Ali, S.; Rizwan, M.; Rehman, M.Z.U.; Javed, M.R.; Imran, M.; Chatha, S.A.S.; Nazir, R. Zinc oxide nanoparticles alter the wheat physiological response and reduce the cadmium uptake by plants. Environ. Pollut. 2018, 242, 1518-1526. [CrossRef] [PubMed]

28. Sedghi, M.; Hadi, M.; Toluie, S.G. Effect of nano zinc oxide on the germination parameters of soybean seeds under drought stress. Ann. West Univ. Timis. 2013, 16, 73-78.

29. Torabian, S.; Zahedi, M.; Khoshgoftar, A.H. Effects of foliar spray of two kinds of zinc oxide on the growth and ion concentration of sunflower cultivars under salt stress. J. Plant Nutr. 2016, 39, 172-180. [CrossRef]

30. Fathi, A.; Zahedi, M.; Torabian, S.; Khoshgoftar, A. Response of wheat genotypes to foliar spray of $\mathrm{ZnO}$ and $\mathrm{Fe}_{2} \mathrm{O}_{3}$ nanoparticles under salt stress. J. Plant Nutr. 2017, 40, 1376-1385. [CrossRef]

31. Sharifan, H.; Ma, X.; Moore, J.M.; Habib, M.R.; Evans, C. Zinc oxide nanoparticles alleviated the bioavailability of cadmium and lead and changed the uptake of iron in hydroponically grown lettuce (Lactuca sativa L. var Longifolia). ACS Sustain. Chem. Eng. 2019, 7, 16401-16409. [CrossRef]

32. Chen, J.; Liu, X.; Wang, C.; Yin, S.; Li, X.; Hu, W.; Simon, M.; Shen, Z.; Xiao, Q.; Chu, C. Nitric oxide ameliorates zinc oxide nanoparticles-induced phytotoxicity in rice seedlings. J. Hazard. Mater. 2015, 297, 173-182. [CrossRef] [PubMed]

33. Yang, Z.; Chen, J.; Dou, R.; Gao, X.; Mao, C.; Wang, L. Assessment of the phytotoxicity of metal oxide nanoparticles on two crop plants, maize (Zea mays L.) and rice (Oryza sativa L.). Int. J. Environ. Res. Public Health 2015, 12, 15100-15109. [CrossRef] [PubMed]

34. Badea, C.; Basu, S. The effect of low temperature on metabolism of membrane lipids in plants and associated gene expression. Plant Omics 2009, 2, 78-84.

35. Lv, Y.; Hussain, M.A.; Luo, D.; Tang, N. Current understanding of genetic and molecular basis of cold tolerance in rice. Mol. Breed. 2019, 39, 159. [CrossRef]

36. Jeong, S.W.; Sun, M.C.; Dong, S.L.; Sang, N.A.; Park, Y.I. Differential susceptibility of photosynthesis to light-chilling stress in rice (Oryza Sativa L.) depends on the capacity for photochemical dissipation of light. Mol. Cells 2002, 13, 419-428.

37. Lu, X.; Song, S.; Xiao, Y.; Fan, F.; Peng, J. Circadian clock-coordinated response to chilling stress in rice. Environ. Exp. Bot. 2021, 185, 104398. [CrossRef]

38. Ryter, S.W.; Kim, H.P.; Hoetzel, A.; Park, J.W.; Nakahira, K.; Wang, X.; Choi, A.M. Mechanisms of cell death in oxidative stress. Antioxid. Redox Sign. 2007, 9, 49-89. [CrossRef]

39. Wang, G.J.; Miao, W.; Wang, J.Y.; Ma, D.R.; Li, J.Q.; Chen, W.F. Effects of exogenous abscisic acid on antioxidant system in weedy and cultivated rice with different chilling sensitivity under chilling stress. J. Agron. Crop Sci. 2013, 199, 200-208. [CrossRef]

40. Ding, Y.; Gong, S.; Wang, Y.; Wang, F.; Bao, H.; Sun, J.; Cai, C.; Yi, K.; Chen, Z.; Zhu, C. MicroRNA166 modulates cadmium tolerance and accumulation in rice. Plant Physiol. 2018, 177, 1691-1703. [CrossRef]

41. Fan, J.; Shi, M.; Huang, J.Z.; Xu, J.; Wang, Z.D.; Guo, D.P. Regulation of photosynthetic performance and antioxidant capacity by 60Co $\gamma$ irradiation in Zizania latifolia plants. J. Environ. Radioactiv. 2014, 129, 33-42. [CrossRef]

42. Jiang, M.; Jiang, J.; Li, S.; Li, M.; Tan, Y.Y.; Song, S.Y.; Shu, Q.Y.; Huang, J.Z. Glutamate alleviates cadmium toxicity in rice via suppressing cadmium uptake and translocation. J. Hazard. Mater. 2020, 384, 121319. [CrossRef] [PubMed]

43. Tang, L.; Cai, H.; Ji, W.; Luo, X.; Wang, Z.; Wu, J.; Wang, X.; Cui, L.; Wang, Y.; Zhu, Y.; et al. Overexpression of GsZFP1 enhances salt and drought tolerance in transgenic alfalfa (Medicago sativa L.). Plant Physiol. Bioch. 2013, 71, 22-30. [CrossRef] [PubMed]

44. He, J.; Duan, Y.; Hua, D.; Fan, G.; Wang, L.; Liu, Y.; Chen, Z.; Han, L.; Qu, L.J.; Gong, Z. DEXH Box RNA Helicase-mediated mitochondrial reactive oxygen species production in Arabidopsis mediates crosstalk between abscisic acid and auxin signaling. Plant Cell 2012, 24, 1815-1833. [CrossRef]

45. Aebi, H. Catalase in vitro. Method Enzymol. 1984, 105, 121-126.

46. Hossain, M.A.; Hasanuzzaman, M.; Fujita, M. Up-regulation of antioxidant and glyoxalase systems by exogenous glycinebetaine and proline in mung bean confer tolerance to cadmium stress. Physiol. Mol. Biol. Plants 2010, 16, 259-272. [CrossRef] [PubMed]

47. Duan, J.; Zhang, M.; Zhang, H.; Xiong, H.; Liu, P.; Ali, J.; Li, J.; Li, Z. OsMIOX, a myo-inositol oxygenase gene, improves drought tolerance through scavenging of reactive oxygen species in rice (Oryza sativa L.). Plant Sci. 2012, 196, 143-151. [CrossRef] [PubMed]

48. Jiang, M.; Wu, X.J.; Song, Y.; Shen, H.Z.; Cui, H.R. Effects of OsMSH6 mutations on microsatellite stability and homeologous recombination in rice. Front. Plant Sci. 2020, 11, 220. [CrossRef]

49. Jiang, M.; Dai, S.; Wang, B.Q.; Xie, Z.M.; Li, J.L.; Wang, L.Y.; Li, S.; Tan, Y.Y.; Tian, B.; Shu, Q.Y.; et al. Gold nanoparticles synthesized using melatonin suppress cadmium uptake and alleviate its toxicity in rice. Environ. Sci-Nano 2021. [CrossRef]

50. Livak, K.J.; Schmittgen, T.D. Analysis of relative gene expression data using real-time quantitative PCR and the 2(-delta delta c (t)) method. Methods 2001, 25, 402-408. [CrossRef] 